\title{
DNA flow cytometry of follicular non-Hodgkin's lymphoma
}

\author{
J C Macartney, R S Camplejohn, R Morris, K Hollowood, D Clarke, A Timothy
}

\begin{abstract}
S-phase fraction, an index of cellular proliferation, and DNA ploidy were measured by DNA flow cytometry in a retrospective study of lymph node biopsy specimens from 83 cases (before treatment) of follicular non-Hodgkin's lymphoma, Working Formulation categories $B$ and $C$. The correlations between these measures and survival, clinical stage, symptoms and histopathological factors were investigated. Aneuploidy was rare $(n=16)$ and had no effect on length of survival or transformation to high grade lymphoma. The overall mean S-phase fraction was $3.6 \%$; for the whole series increasing $S$-phase fraction was associated with decreased survival. A high S-phase fraction (more than $5 \%$ ) in initial biopsy specimens was also associated with an increased risk of subsequent high grade transformation at relapse. There was no difference between the survival or proliferative activity of tumours composed of mainly small cleaved cells compared with those composed of mixed small and large cells. There was no difference in survival or proliferative activity between tumours showing a pure follicular growth pattern and those with a mixed follicular and diffuse growth pattern. Multifactorial analysis showed that an S-phase fraction of more than $5 \%$ and $B$ symptoms were the most important factors determining survival in these follicular non-Hodgkin's lymphomas.
\end{abstract}

Since the early studies of Peckham and Cooper ${ }^{1}$ it has been repeatedly shown that low grade non-Hodgkin's lymphomas (NHL) exhibit overall lower proliferative activity than high grade $\mathrm{NHL}^{2}{ }^{2}$ In view of the different prognoses of high and low grade NHL it is hardly surprising, therefore, that the degree of proliferative activity is inversely related to the length of survival. If this effect is merely linked to histopathological grade, however, there is little reason to measure proliferation. The measurement of proliferation by either DNA flow cytometry, 3H-thymidine labelling index, or $\mathrm{Ki}-67$ score becomes clinically relevant when it can be shown that the result has an independent prognostic effect within homogenous subtypes of NHL of similar grade.

In this study we examined the effect of proliferative activity on the prognosis of follicular NHL. Characteristically follicular NHL are low grade indolent tumours of follicle centre B lymphocytes which are often widely disseminated at presentation, relapse frequently, and may undergo transformation to high grade NHL ${ }^{3}$ Because of the unpredictable behaviour exhibited by some cases of follicular NHL it would be advantageous to select cases with a worse prognosis for more aggressive treatment. Using flow cytometry Griffin et al showed a significant effect of proliferative activity on the prognosis of follicular $\mathrm{NHL}^{4}$; and in our previous study ${ }^{5}$ of a small number of cases, high proliferative activity in initial biopsy specimens was associated with subsequent transformation at relapse. Neither study took into account clinical prognostic variables.

We have now examined a larger group of low grade follicular lymphomas using DNA flow cytometry of archival histopathological material and present evidence that proliferative activity has an independent effect on prognosis.

\section{Methods}

A retrospective DNA flow cytometric study of 83 patients with low grade follicular NHL diagnosed between 1961 and 1987 at St Thomas's Hospital was undertaken. In all 83 cases biopsy material before treatment was available for flow cytometry and histological classification. For 22 of the 83 cases biopsy material was also available from subsequent relapses. Information to determine clinical stage, treatment, remission, clinical relapse and overall survival were obtained from the clinical notes. The demographic data for the series are shown in table 1.

\section{HISTOPATHOLOGY}

Histological sections were stained with haematoxylin and eosin, Giemsa, and for reticulin. All cases were also stained immunohistochemically with MB1, MB2, and L26 monoclonal antibodies to confirm a $B$ cell lineage.

Cases were subclassified cytologically (table 2) using the Working Formulation ${ }^{6}$ into those composed predominantly of small cleaved cells (category B in the Working Formulation) and a mixed small and large cell group (category $\mathrm{C}$ in the Working Formulation). Cases consisting of follicular lymphomas with either a clear predominance of large cells or composed wholly of large cells were specifi-

Correspondence to:

Accepted for publication

31 October 1990 
Table 1 Clinical features of patients with follicular lymphomas

\begin{tabular}{ll}
\hline Men & $\mathrm{n}=43$ \\
Women & $\mathrm{n}=40$ \\
Mean age at presentation & $55 \cdot 5$ years $(21 \cdot 4-80 \cdot 3)$ \\
Median follow up & 45 months \\
Clinical stage: & \\
1 & $\mathrm{n}=17$ \\
2 & $\mathrm{n}=9$ \\
3 & $\mathrm{n}=19$ \\
4 & $\mathrm{n}=21$ \\
Not known & $\mathrm{n}=17$ \\
Clinical symptoms: & $\mathrm{n}=62$ \\
A & $\mathrm{n}=21$ \\
B & $\mathrm{n}=12$ \\
Treatment: & $\mathrm{n}=22$ \\
Observation & $\mathrm{n}=34$ \\
Radiotherapy & $\mathrm{n}=7$ \\
"Mild" chemotherapy & $\mathrm{n}=8$ \\
"Aggressive" chemotherapy & \\
Not known & \\
\hline
\end{tabular}

Table 2 Comparison of S-phase fractions in various histological subtypes

\begin{tabular}{|c|c|c|}
\hline & $\begin{array}{l}\text { Mean S-phase fraction } \\
\text { ( } 95 \% \text { confidence limits) }\end{array}$ & Probability \\
\hline All cases $(n=83)$ & $3 \cdot 6 \quad(3 \cdot 1-4 \cdot 0)$ & \\
\hline $\begin{array}{l}\text { Architectural subtype: } \\
\quad \text { follicular }(n=69) \\
\text { follicular and diffuse }(n=14)\end{array}$ & $\left.\begin{array}{ll}3 \cdot 5 & (3 \cdot 0-4 \cdot 0) \\
4 \cdot 2 & (0 \cdot 8-10)\end{array}\right\}$ & NS \\
\hline $\begin{array}{l}\text { Cytological subtype: } \\
\text { small cell }(n=61) \\
\text { mixed }(n=22)\end{array}$ & $\left.\begin{array}{ll}3 \cdot 3 & (2 \cdot 9-3 \cdot 8) \\
4 \cdot 4 & (3 \cdot 2-5 \cdot 7)\end{array}\right\}$ & NS \\
\hline $\begin{array}{l}\text { First biopsy: } \\
\text { untransformed at relapse }(n=12) \\
\text { transformed at relapse }(n=10)\end{array}$ & $\left.\begin{array}{ll}2.5 & (1 \cdot 7-3 \cdot 3) \\
5.0 & (3 \cdot 4-6 \cdot 6)\end{array}\right\}$ & 0.01 \\
\hline
\end{tabular}

cally excluded from the series because they are generally considered to be of higher grade malignancy. Similarly, cases with a pure diffuse architecture or cases of centrocytic lymphoma ${ }^{7}$ were also excluded from the series. Cases were also subdivided into those which showed either a pure follicular architecture or a combined follicular and diffuse architecture in the same biopsy specimen. The number of cases showing clinically important sclerosis was documented as this is reported to be of prognostic value. $^{8}$

\section{DNA FLOW CYTOMETRY}

DNA flow cytometry was performed using samples prepared from archival paraffin wax blocks. The method for preparation was slightly modified from that of Hedley et al ${ }^{9}$ and has been described previously. ${ }^{10}$ We have shown that results obtained by this method correlate highly with results obtained from fresh lymphoid tissue. ${ }^{1011}$ Briefly, $50 \mu \mathrm{m}$ sections were dewaxed, rehydrated, and incubated in pepsin for 30 minutes at $\mathrm{pH} 1.5$. The resulting suspension was centrifuged and the pellet resuspended in Isoton containing $1 \mu \mathrm{g} / \mathrm{ml}$ of 4,6-diamidino-2-phenylindolhydrochloride. The suspension was then syringed through a narrow gauge needle and filtered through $35 \mu \mathrm{m}$ pore size nylon gauze. Ten thousand cells per sample were analysed on a Beckton Dickinson FACS analyser.

Tumours were considered to be DNA aneuploid if two distinct $G_{1} / G_{0}$ peaks were present. A DNA index of 1.0 indicates the presence of only diploid cells which have a normal amount of DNA. A full peak coefficient of variation (CV) was calculated for the $G_{1} / G_{0}$ peak. The mean $C V$ for the whole series was 3.9. For reasons discussed previousiy, ${ }^{11}$ cytometric readings with a high $\mathrm{CV}$ (more than 8.0) were considered unacceptable. The proportion of cells synthesising DNA (S-phase fraction) was calculated by the method of Baisch ${ }^{12}$ for cases which were DNA diploid. In cases which were DNA aneuploid the S-phase fraction was calculated using the methods described by Camplejohn and Macartney. ${ }^{11}$

Outcome was assessed in terms of overall survival and relapse-free survival. The effects of histological pattern, cytological group, clinical stage, A and B symptoms, DNA ploidy and S-phase fraction on survival were analysed separately using life tables. Histological subtypes were compared for survival using the log rank test ${ }^{13}$ and S-phase fractions in different groups were compared using the Wilcoxon rank sum test. To examine the independent effect of these factors on survival and to allow for varying lengths of follow up, Cox's proportional hazards model was applied. ${ }^{14}$

\section{Results}

Tables 1 and 2 show general characteristics for the whole series of 83 cases and the numbers of cases falling into various histological subtypes. The projected median survival for the whole series was 7.6 years. Complete remission was achieved in $51 \%$ of cases and the median remission duration was 1.7 years. Forty four per cent of those achieving remission, however, subsequently relapsed. Because there was no consistent policy of taking biopsy specimens from patients to document relapse, histological material was available for only 22 of the patients who relapsed. At rebiopsy, 10 of these patients had transformed into high grade NHL while the remainder still showed low grade follicular NHL. In the main series there was no difference in survival between the cases falling into the various histological subtypes or clinical stages, although there was a trend for cases with mixed small and large cell histology to do slightly worse. Only eight cases showed clinically important sclerosis and there was no difference in either their survival or S-phase fraction compared with the main group. The survival of patients with B symptoms (median 21 months) was significantly ( $p=0.02$ ) worse than those with A symptoms.

\section{PLOIDY}

DNA aneuploidy was found in 16 of the 83 cases and the most common aneuploid DNA index was $1 \cdot 1(n=7)$. There was no difference in survival between DNA diploid and aneuploid cases and there was no difference in the incidence of aneuploidy between various histological subtypes or clinical stages.

\section{PROLIFERATIVE ACTIVITY}

The mean S-phase fraction for the whole series of 83 patients was $3.6 \%$ with a median of $3.0 \%$ (table 2). There was no difference between the $S$-phase fractions seen in various histological 


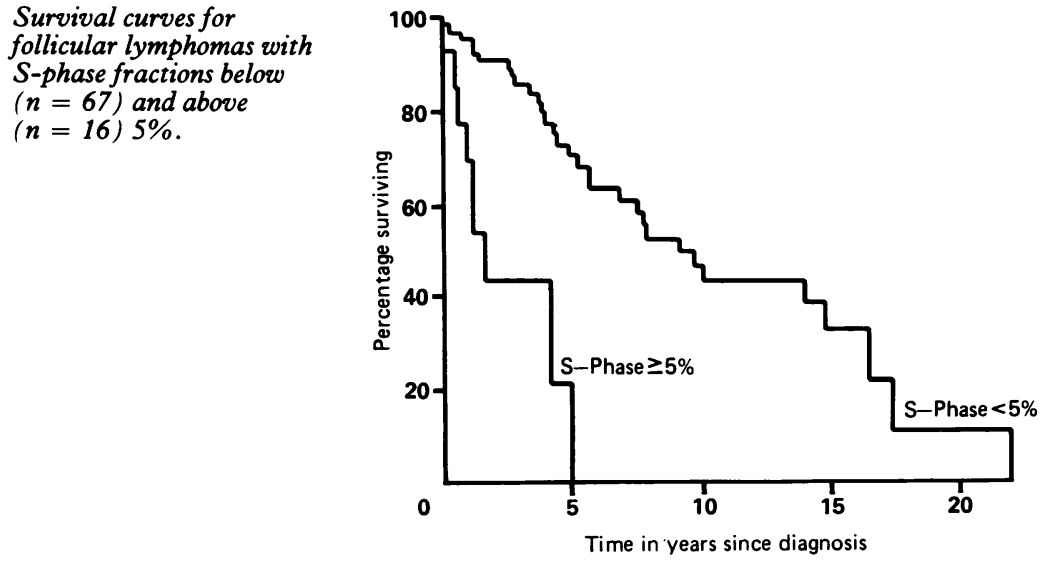

subtypes (table 2). Because of this, cases were grouped together for further analysis. This showed a significant $(p=<0.01)$ difference in the survival of cases with $S$-phase fractions of at least $5 \%$ compared with less proliferative cases (figure). This difference in survival was seen when comparisons were made between tumours with proliferative activity above and below $5 \%$ or when S-phase was treated as a continuous variable. Multifactorial analysis showed that only S-phase fraction and the presence of B symptoms significantly affected the overall survival. Analysis was also stratified by decade of diagnosis, but this did not affect the observations reported for S-phase or ploidy. As in our previous study, cases which subsequently underwent a documented high grade transformation had a significantly higher $S$-phase fraction in their initial biopsy specimens at the time of first presentation (table 2), reflecting the important effect of S-phase on survival.

\section{Discussion}

Several factors are reported to have a prognostic effect in follicular NHL. They include the presence of anaemia, abnormal liver function tests, B symptoms, increasing age, advanced stage, increasing tumour bulk and poor response to treatment. ${ }^{315-17}$ Histologically, the proportion of large cells, mitotic index, and the presence or absence of a mantle zone have also been claimed to have a prognostic effect. ${ }^{15}{ }^{18-22}$ In general, growth pattern has no significant effect, although some authors report a trend to poorer survival in diffuse tumours. To circumvent some of the problems associated with the morphological heterogeneity of follicular lymphomas and achieve a more homogenous group of cases we excluded from our study cases with a diffuse architecture or those with a high content of large cells.

Because this was a retrospective study patients did not receive uniform pretreatment assessments or standard treatment protocols. We were therefore unable to consider certain prognostic factors such as disease bulk in our analysis, and clinical staging data were only available for $80 \%$ of cases. This also probably accounts for the rather high percentage of stage 1 cases in the series. The inclusion of cases spread over a 25 year period would be unacceptable if high grade NHL were under consideration because of changes in treatment during this time. Therapeutic options for low grade follicular NHL, however, have not changed substantially, and we were unable to detect any difference in survival between cases diagnosed during the first and second half of the period studied.

Several studies have previously suggested that proliferative activity, measured by flow cytometry, Ki67 index, or mitotic index, affects the prognosis of follicular NHL. In these studies, however, the grouping of cases for analysis has often included a mixture of low grade lymphomas and results are not specific for follicular lymphomas. ${ }^{23-25}$ Alternatively, the effects of all the other factors such as symptoms, stage, histological subtype and architecture have not been studied or numbers are small. 45202627

The major finding of our study is that proliferative activity seems to be the most important factor governing survival in follicular NHL, confirming previous more limited studies. ${ }^{4527}$ DNA aneuploidy was rare and had no prognostic effect. We also confirmed our previous finding that tumours with high proliferative activity in the initial biopsy specimen (more than $5 \%$ ) were more likely to sustain high grade relapse.

Our results have implications for the treatment of follicular NHL. Although the decision to treat this disease must be based on consideration of factors such as symptoms, nevertheless the results presented here do provide an argument for treating follicular NHL with high proliferative activity with more aggressive therapeutic regimens.

We thank Jackie Pilgrim for typing the manuscript, Fion Macefield and Karl Hobbs for excellent technical assistance, an Miss S Mandalia for help with data analysis. We are grateful to the physicians and surgeons of St Thomas's Hospital for permission to publish clinical data on their patients.

1 Peckham M, Cooper EH. The pattern of cell growth in reticulum cell sarcoma and lymphosarcoma. Eur J Cancer 1970;6:453-63.

2 Macartney JC, Camplejohn RS. DNA flow cytometry of non-Hodgkin's lymphoma. Eur J Clin Oncol 1990;26: 635-7.

3 Gallagher CJ, Gregory WM, Jones AE, et al. Follicular ymphoma: prognostic factors for response and survival. $J$ Clin Oncol 1986;4:1470-80.

4 Griffin NR, Howard MR, Quirke P, et al. Prognostic indicators in centroblastic-centrocytic lymphoma. J Clin Pathol 1988;41:866-70.

5 Macartney JC, Camplejohn RS, Alder J, et al. Prognostic importance of DNA flow cytometry in non-Hodgkin's lymphomas. J Clin Pathol 1986;39:542-6.

6 The non-Hodgkin's lymphoma pathologic classification project. National Cancer Institute sponsored study of project. National Cancer Institute sponsored study of and description of a Working Formulation for clinical and description of a Working

7 Lennert K. Malignant lymphomas other than Hodgkin's disease. Berlin: Springer-Verlag, 1978.

8 Bennett MH. Sclerosis in non-Hodgkin's lymphomas. Br J Cancer 1975;31(Suppl II):44-52.

9 Hedley DW, Friedlander ML, Taylor IW, et al. Method for analysis of cellular DNA content of paraffin-embedded pathological material using flow cytometry. J Histochem Cytochem 1983;31:1333-5.

10 Camplejohn RS, Macartney JC. Comparison of DNA flow cytometry from fresh and paraffin embedded samples of cytometry from fresh and parafin embedded samples of

11 Camplejohn RS, Macartney JC. S-phase fractions in lym phoid tissue: fresh versus paraffin-embedded tissue and phoid tissue: fresh versus paraffin-embedded tissue and

12 Baisch H, Gohde W, Linden WA. Analysis of PCP-data to determine the fraction of cells in the various phases of cell 
cycle. Radiat Environ Biophys 1975;12:31-9.

13 Peto R, Pike MC, Armitage P, et al. Design and analysis of randomized clinical trials requiring prolonged observation of each patient. II. Analysis and examples. $B r J$ Cancer 1977;35:1-39.

14 Armitage P, Berry G. Statistical methods in medical research. 2nd edition. Oxford: Blackwell, 1987:436-7.

15 Stein RS, Cousar J, Flexner JM, et al. Malignant lymphomas of follicular center origin in man III. Prognostic phomas of follicular center origin

16 Brittinger G, Bartels $\mathrm{H}$, Common $\mathrm{H}$, et al. Clinical and prognostic relevance of the Kiel Lymphoma Study prognostic relevancel Hematol Oncol 1984;2:269-306.

17 Gospodarowicz MK, Bush RS, Brown TC, et al. Prognostic factors in nodular lymphomas: a multivariate analysi based on the Princess Margaret Hospital experience. Int Radiat Oncol Biol Phys 1984;10:489-97.

18 Ezdinli EZ, Costello WG, Icli F, et al. Nodular mixed lymphocytic-histiocytic lymphoma (NM). Response and survival. Cancer 1980;45:261-7.

19 Paryani SB, Hoppe RT, Cox RS, et al. Analysis of nonHodgkin's lymphomas with nodular and favourable histologies, stage I and II. Cancer 1983;52:2300-7.

20 Ellison DJ, Nathwani BN, Metter GE, et al. Mitotic counts in follicular lymphomas. Hum Pathol 1987;18:502-5.

21 Akerman M, Brandt L, Johnson A, et al. Mitotic activity in non-Hodgkin's lymphoma. Relation to the Kiel classification and to prognosis. Br $J$ Cancer 1987;55:219-23.

22 West KP, Potter LJ, Henderson SD, et al. A retrospective study of follicular lymphoma. Histopathol 1989;14: 629-36.

23 Christensson B, Tribukait B, Linder I-L, et al. Cell proliferation and DNA content in non-Hodgkin's proliferation and DNA content in non-Hodgkin's
lymphoma. Flow cytometry in relation to lymphoma lymphoma. Flow cytometry in relation

24 Hall PA, Richards MA, Gregory WEM, et al. The prognostic value of Ki67 immunostaining in non-Hodgkin's lymphoma. J Pathol 1988;154:223-36.

25 Lehtinen $T$, Aine $R$, Lehtinen $M$, et al. Flow cytometric DNA analysis of 199 histologically favourable or unfavourable non-Hodgkin's lymphomas. J Pathol 1989, 157:27-36.

26 Costa A, Bonadonna G, Villa E, et al. Labelling index as a prognostic marker in non-Hodgkin's lymphoma. JNCI $1981 ; 66: 1-5$.

27 Rehn S, Glimelius B, Strang P, et al. Prognostic significance of flow cytometry studies in B-cell non-Hodgkin's lymphomas. Hematol Oncol 1990;8:1-12.

\section{Eponyms in pathology ...}

RICKETTS, Howard Taylor (1871-1910) was an American microbiologist and epidemiologist who qualified from Northwestern university in 1897, later working in the department of pathology at the university of Chicago. He carried out important field studies on Rocky Mountain Spotted Fever and showed that the causative organism is transmitted to man by the bite of a wood tick. These small bacillus-like parasites were grouped together under the name rickettsia by $\mathrm{Da}$ Rocha-Lima in honour of Ricketts. Ironically, he died of typhus fever (another rickettsial infection) while studying it in Mexico City in 1910.
ASKANAZY, Max (1865-1940) was a Swiss pathologist, born in East Prussia, and educated in Konigsberg, West Germany. He became professor of general pathology in Geneva in 1905, and his major contributions were in the fields of haematology, parasitology, and oncology. His description of the large granular eosinophilic cell derived from the thyroid follicular epithelium is the same as that of Hürthle (a German histologist, 1860-1945) and the two eponyms are synonymous with the term "oxyphil cell". 